\section{Imanishi-Kari (continued)}

SIR - Wortis et al. say (Nature 351, 514; 1991) that I could not have known that, at their meeting with Dr Imanishi-Kari on 16 May 1986, they were not shown authentic data on which Table 2 in the disputed Cell paper may have been based. Correctly, they say that I was not present. These are the data, also called the June sub-cloning data', 'that are alleged by the draft Office of Scientific Integrity (OSI) report to have been fabricated. So the question is whether the Wortis committee was shown these data, and was misled by them, by some other data or by no data at all.

If the committee had been shown data supporting the claims embodied in Table 2 , it is mystifying that it did not say as much in the report requested by the National Institutes of Health (NIH) in 1987, when the validity of Table 2 had already been questioned.

The committee now says that it accepted on 16 May 1986 that the then acknowledged deficiencies of Table 2 were mitigated by the existence of data from unpublished experiments. But did they not have a duty to disclose this circumstance when reporting to the Tufts community and to NIH as well as in their 1988 interviews with the Dingell committee staff?

An explanation is also required (not necessarily from Wortis et al.) of this circumstance: by their account, at a meeting arranged at only one day's notice, with no advance warning of the issues to be raised, Dr Imanishi-Kari is said to have produced evidence that convinced the committee that "Dr O'Toole's concerns could be answered"; yet two years later, despite detailed written warning of the questions to be raised, Imanishi-Kari did not produce or even mention to the NIH panel the data that had supposedly allayed the Wortis committee's concerns, but said only after the interview that there were such data.

It is also puzzling that some of the data records produced at the second meeting on 23 May 1986 (at which I was present) have been shown, by indentation analysis carried out by the Secret Service, not to have existed one week earlier. I cannot understand why data that the members of the Wortis committee now say convinced them on 16 May that my concerns were unwarranted should not have been produced for me to see at the meeting a week later, but instead should have been replaced by other data records written during the interval.

I believe that these questions will be answered in due course, and that it will then emerge that the only unpublished data supporting the claims in existence 560 on 23 May 1986 were those shown to me on that day, and that the more complete answer to my challenge presented to the Dingell committee was fabricated much later.

Newton,

Massachusetts 02160, USA

\section{Chauvinism}

SIR - Publication bias, several forms of which have been described ${ }^{1,2}$, may distort the scientific literature. On the hypothesis that there is a 'national publication bias' in which journals favour the printing of papers coming from the same country, we have examined all original papers published during 1990 in one British, one Swedish, one US and one German journal. All journals were related to our field of research (physical medicine and rehabilitation) and were listed in Current Contents; all were in English, except for one published in Germany, which merely had English abstracts. Each paper was classified according to the address of the first author. The table shows that the nationality of each journal is strongly associated with the nationality of its authors.

PERCENTAGE OF FIRST AUTHORS OF ORIGINAL ARTICLES

\begin{tabular}{llll}
\hline Address of & $\begin{array}{l}\text { National } \\
\text { journal }\end{array}$ & $\begin{array}{l}\text { Foreign } \\
\text { authors }\end{array}$ & $\begin{array}{l}\text { Impact } \\
\text { factor }\end{array}$ \\
UK & 59.6 & 40.4 & 1.6 \\
Sweden & 42.4 & 57.6 & 0.3 \\
USA & 79 & 21 & 0.6 \\
Germany & 56 & 44 & 0.0 \\
\hline
\end{tabular}

This relationship is not uniform. According to the present data, it is strongest in the United States. All other countries follow at considerable and similar distance.

Clearly, these results need to be confirmed on a broader basis using data of many more publications. Yet we suspect that the 'national publication bias' is highly prevalent in the scientific literature. It is of some concern in a world where research should be a free and international matter and could have at least two worrying effects. (1) It might lead to a false representation of scientific opinions according to one nation's preference; if, for example, one form of therapy is neglected in the United States (as calcium channel blockers were several years ago), that would cause a general under-representation of that treatment in the medical literature, which is dominated by US journals with high impact factors. (2) Professional career decisions are now often influenced by impact factors and other measures of scientific output, so that the bias is unfair to scientists who come from countries where journals rarely have high ratings. If the 'national publication bias' can be confirmed to exist, editors should change their policies and university bodies should think of ways to minimize its harmful effects.

Department of Physical

E. ERNST

T. KIENBACHER and Medical Rehabilitation,

University of Vienna, A-1097 Vienna, Austria

1. Easterbrook, P.J., Berlin, J.A., Gopalan, R. \& Matthews, D.R. Lancet 337, 867-72; 1991.

. Andersen, B. Methodological Errors in Medical Research (Blackwelt, Oxford, 1990).

\section{Magnetic machine}

SIR - I wish to clarify and correct what Christopher Anderson says (Nature 352, $270 ; 1991)$ about the susceptometer that this company supplied to the superconductivity Interdisciplinary Research Centre (IRC) at Cambridge.

Far from believing itself bound to buy a British susceptometer from this company rather than the US unit, the IRC bought one of each. Our machine is optimized for weak signals at the lowest magnetic fields. The S100 susceptometer built for the IRC was delivered two years after order but not two years late; it was ordered on a delivery time anticipated to be 14 months.

It is true that the Cryogenic susceptometer was only in the development stage at the time the IRC placed its order, but since then ten systems have been delivered to customers around the world, including the United States and Japan. Once installed correctly, the machines have proved reliable and have been easy to operate and support; customers seem well pleased with the performance.

Not all these machines are used for superconductivity research; the original design produced by both the British and US companies lacked an important feature relevant to research on superconductors. In the normal mode of operation, the sample is moved a relatively long distance, more than $10 \mathrm{~cm}$, and so suffers a change in applied magnetic field during each measurement. This makes it impossible to obtain true magnetic hysteresis loops. To overcome this difficulty, a short scan facility is being provided in which the sample is moved only about 1 $\mathrm{cm}$ and remains in a uniform magnetic field. Our company is providing this extra facility free of charge to the IRC at Cambridge, although it was not originally specified. Incidentally, the price was not $£ 100,000$ but less than $£ 80,000$ for the option chosen by the IRC.

JEREMY GOOD

Cryogenic Consultants Limited, Metrostore Building, 231 The Vale, London W3 7QS, UK 